\title{
Entre Luzes e Sombras: o Rio de Janeiro dos Megaeventos e a militarização da vida na cidade
}

\author{
Lia de Mattos Rocha ${ }^{1}$ \\ Jonathan Willian Bazoni da Motta²
}

\section{Resumo}

Neste artigo analisamos - tendo o Rio de Janeiro sob o "ciclo dos megaeventos" como cenário - a produção da Cidade Olímpica como um "jogo de luz e sombra". Por um lado, uma parte da cidade esteve sob os holofotes, recebendo atenção da academia, da imprensa, dos atores políticos institucionais etc. - representada pela Cidade Olímpica. Por aqui, observamos os efeitos da transformação do Rio em uma "cidade de negócios" (marketing city) e, assim, analisamos as imbricações entre esse processo e a expansão do que chamamos de "militarização da vida", especialmente nas favelas "pacificadas". Por outro lado, uma importante parte da cidade foi colocada à "sombra" nesse processo: a Zona Oeste. Geralmente descrita sob o signo da ausência (de urbanização, de modernidade), nesta parte da cidade moram quatro entre cada dez cariocas. Apesar disso, ela esteve "apagada" de praticamente todas as representações do Rio no contexto olímpico. Utilizando pesquisa de campo realizada em localidades dessa região, bem como a análise de material da imprensa e da bibliografia pertinente, argumentamos que tal apagamento não significa que nada aconteceu na Zona Oeste durante os dez anos que durou o "ciclo dos megaeventos". Por ali, observouse, sobretudo, a expansão das milícias, grupos armados majoritariamente compostos por exmilitares. Investigamos, nesse sentido, as variadas formas adotadas pelas milícias na região, bem como os efeitos dessa presença para os moradores. Como conclusão, argumentamos que "luz" e "sombra" se produzem mutuamente no Rio de Janeiro atual, pois representam diferentes regimes territoriais que compõem a cidade. Argumentamos ainda que é fundamental para compreender o "jogo de luz e sombra" a conexão entre megaeventos e militarização, ambos fenômenos mundiais com expressões locais específicas, sendo as milícias uma expressão local da militarização experimentada em escala global.

\section{Palavras-chave}

Rio de Janeiro. Megaeventos. Militarização.

\footnotetext{
${ }^{1}$ Professora do Departamento de Sociologia e Pós-Graduação em Ciências Sociais/UERJ. E-mail: lia.rocha@uerj.br.

${ }^{2}$ Mestrando em Ciências Sociais pelo Programa de Pós-Graduação em Ciências Sociais da UFRRJ. E-mail: jonathan.jntn@gmail.com.
} 


\begin{abstract}
We analyze in this article the crafting of Rio de Janeiro as the Olympic City, during the "mega-events cycle", interpreting this process as a "game of light and shadows". On one hand, a part of the city was under the spotlight, receiving attention from the academy, the press, the institutional political actors etc. - represented by the Olympic City. Here, we observe the effects of Rio's transformation into a "marketing city", and so we analyze the implications between this process and the expansion of what we call the "militarization of life", especially in "pacified" favelas. On the other hand, an important part of the city was put into the "shadows" during this process: The West Zone. Generally described as an area of absence (lack of urbanization, modernization), four out of ten Rio's dwellers live there. Despite that, it has been "erased" from almost every representation of the city in the Olympic context. Using field research conducted in this area, as well as the analysis of press material and relevant bibliography, we argue that such effacing does not mean that nothing happened in the West Zone during the ten years of the "mega-events cycle". In that area, we mostly observed the expansion of the militias, armed groups mainly composed of former militaries. Thus, we investigated the various forms adopted by the militias in the region, as well as the effects of its presence on residents. In conclusion, we argue that "light" and "shadow" mutually coproduce each other in Rio de Janeiro currently, as they represent different territorial regimes that compose the city. Furthermore, we argue that, to understand this "game of light and shadow", the connection between mega-events and militarization is crucial. Both are a worldwide phenomena with specific local expressions, the militias being a local expression of militarization.
\end{abstract}

\title{
Keywords
}

Rio de Janeiro. Mega-events. Militarization.

\section{Introdução}

Em 2007, o Brasil foi escolhido país-sede da Copa do Mundo de Futebol da Federação Internacional de Futebol (Fifa), que seria realizada em 2014, e o Rio de Janeiro foi anfitrião dos Jogos Pan-Americanos. Dois anos depois, a cidade foi escolhida para ser sede dos Jogos Olímpicos de Verão de 2016. Entre esses dois anúncios, bastante comemorados à época no Brasil e no Rio, foi inaugurado, na favela Santa Marta, localizada em bairro nobre da cidade, um projeto de ocupação militar apresentado como polícia de proximidade, chamado Unidade de Polícia Pacificadora ${ }^{3}$. Assim, em apenas dois anos, conformou-se parte

\footnotetext{
${ }^{3}$ Concomitantemente com o projeto da "pacificação", outras medidas na área da segurança pública foram tomadas posteriormente, como operações de Garantia da Lei e da Ordem, ocupações militares
} 
importante do cenário que modificou a cidade e o país, e cujos efeitos ainda estão sendo experimentados - e também estudados. Em tal cenário, atravessado por dinâmicas sociais, econômicas e políticas, em nível local e nacional, militarização e megaeventos configuram-se mutuamente como condição de possibilidade um do outro, contribuindo para conformar o Rio de Janeiro e o Brasil em que vivemos hoje.

A Copa do Mundo de Futebol e os Jogos Olímpicos são os mais importantes acontecimentos desse "ciclo de megaeventos" (LEITE et. al, 2018, p. 11), mas não são os únicos: a partir de 2007, aconteceram na cidade também os Jogos PanAmericanos (2007); os Jogos Mundiais Militares (2011); e a Jornada Mundial da Juventude (2013) (ROCHA, 2018, p. 237). A realização de tantos eventos em um período tão curto, tendo a cidade do Rio de Janeiro como palco, modificou seu tecido urbano 4 e produziu um contexto político em que a imagem da Cidade Olímpica expressou um projeto local e nacional caracterizado pelo progresso, desenvolvimento econômico e integração social ${ }^{5}$. Assim, os diferentes atores políticos e econômicos colocaram seus holofotes sobre o Rio Olímpico, transformando esse discurso numa narrativa sobre o nosso "sucesso". No campo da pesquisa social, também orientamos muitos de nossos interesses investigativos - e da nossa capacidade crítica - para pesquisar os efeitos desse processo: remoções, "pacificação" e ordenamentos urbanos sui generis (como no caso das Operações Consorciadas que caracterizaram a região do Porto Maravilha), que foram temas de importantes trabalhos produzidos pela sociologia e antropologia urbanas no período ${ }^{6}$.

Contudo, a mesma dinâmica que jogou luz sobre uma parte dos processos sociais em curso na cidade produziu sombra sobre outros processos, cuja territorialização é bastante marcada: enquanto boa parte de nossas atenções estava voltada para as zonas centrais da cidade, processos sociais profundos se

de favelas, legislação antiterror etc. Na próxima seção essas iniciativas serão apresentadas.

${ }^{4}$ Aqui fazemos menção não apenas aos equipamentos turísticos e esportivos construídos (e alguns já abandonados), como também às novas vias de circulação abertas, à expansão da ocupação e da mercantilização de terras (especialmente na Região Central e Portuária), bem como ao enorme contingente populacional removido. Segundo o Comitê Popular da Copa e Olimpíadas (2013, p. 31), mais de dez mil famílias foram removidas só na cidade. Sobre esses múltiplos efeitos, ver: Magalhães (2013); Fernandes (2014); Pio (2014); Gutterres (2016); Davies (2017).

5 Para compreender a construção do discurso sobre os megaeventos como progresso e desenvolvimento, ver Damo e Oliven (2013).

${ }^{6}$ Além dos trabalhos já citados na nota 2, destacamos: Carvalho (2014); Menezes (2015); Barros (2016), entre outros. 
desenvolviam na Zona Oeste (e na Baixada Fluminense, região metropolitana do Rio de Janeiro ${ }^{7}$ ).

Agora, com o fim do ciclo dos megaeventos e do projeto do Rio Olímpico, o debate sobre as perdas e ganhos que o período possa ter proporcionado foi atropelado pelo tsunami de crises que têm aterrado a sociedade brasileira. No Rio de Janeiro, especificamente, os Jogos Olímpicos já foram realizados sob um "estado de calamidade", decretado pelo governo um mês antes da abertura, alegando grave crise financeira que "imped(iria) o cumprimento das obrigações assumidas em decorrência da realização dos Jogos Olímpicos e Paraolímpicos de 2016"8. E, desde então, a crise econômica e política só se aprofunda.

Um dos temas que tem ocupado as manchetes dos jornais fluminenses, e que entendemos que compõe o cenário de crise rapidamente descrito, é o crescimento da atuação de grupos paramilitares conhecidos como milícias. Segundo o Ministério Público Federal, entre 2010 e 2017, as milícias duplicaram sua área de atuação ${ }^{9}$. Esses grupos armados despertaram maiores atenções da opinião pública em 2007, quando eclodiu o famoso caso do sequestro e tortura dos jornalistas do Jornal Extra na favela do Batan, Zona Oeste, mas seu surgimento é anterior: alguns pesquisadores indentificam as milícias como continuidade dos grupos de extermínio atuantes na Baixada Fluminense nos anos 1960 e 1970 (ALVES, 2008), enquanto outros associam seu início à organização local de moradores da Zona Oeste para o patrulhamento de suas ruas (BURGOS, 2002).

Alguns dos primeiros estudos sobre o tema, particularmente aqueles realizados pela equipe do Laboratório de Análise da Violência da Uerj (CANO; IOOT, 2008; CANO; DUARTE, 2012), foram fundamentais para conceituar o que seriam as milícias, o que permitiu sua tipificação como atividade criminosa e sua penalização, especialmente a partir da Comissão Parlamentar de Inquérito (CPI) das Milícias, instaurada pela Assembleia Legislativa do Rio de Janeiro em 2008. A partir dessas pesquisas definiu-se o que seriam as principais características das milícias: i) domínio territorial; ii) coação de moradores e comerciantes locais para

\footnotetext{
7 No escopo deste artigo não conseguiremos abordar os impactos e efeitos dos contextos dos megaeventos sobre a Baixada Fluminense, região que engloba treze municípios e quase quatro milhões de habitantes (IBGE, 2010). Sobre o tema, ver Miagusko (2016).

${ }^{8}$ Cf. Decreto publicado no Diário Oficial em 17/06/2016. Disponível em: <http://g1.globo.com/riode-janeiro/noticia/2016/06/governo-do-rj-decreta-estado-de-calamidade-publica-devido-

crise.html>. Acesso em: $17 \mathrm{dez}$. 2019. Essa medida administrativa permitiu que o governo "racionalizasse" os serviços públicos prestados à população; ou seja, foram cortados serviços para garantir a realização dos Jogos.

${ }^{9}$ Cf. Jornal O Globo, 10 de Abril de 2018. Disponível em: <https://oglobo.globo.com/rio/em-oitoanos-numero-de-areas-controladas-por-grupos-paramilitares-dobrou-22574503>. Acesso em: $1^{\circ}$ fev. 2019.
} 
exploração econômica (seja através da cobrança direta ou através da intermediação de serviços como venda de terrenos, venda de bujão de gás, fornecimento de água, serviço de TV a cabo, entre outros); iii) legitimação social através do discurso de "combater o tráfico de drogas"; iv) participação de agentes estatais armados. As duas últimas características, ainda segundo esse conjunto de pesquisas, seriam os principais traços de diferenciação das milícias em relação às quadrilhas de tráfico de drogas (CANO; DUARTE, 2012). Os autores identificaram ainda que, após a divulgação dos resultados da $\mathrm{CPI}^{10}$, as milícias passaram a atuar de forma mais discreta, "no sapatinho", já que sua atuação teria ficado deslegitimada.

Todavia, desde então as milícias modificaram sua atuação e estrutura, embaralhando as definições até então estabelecidas. Atualmente, grupos milicianos têm feito alianças com facções que comercializam drogas ilícitas no varejo, têm entrado em confronto com outros grupos armados para controlar territórios na cidade e têm novamente estampado as páginas dos jornais ${ }^{11}$.

Para os objetivos deste artigo, interessa-nos compreender o crescimento da atuação das milícias dentro do contexto de modificações nas dinâmicas sociais e urbanas propiciadas pelo "ciclo dos megaeventos". Conforme apresentado, enquanto se "jogava luz" sobre uma parte da cidade, sobre outra jogavam-se sombras - e foi exatamente aí que as milícias se expandiram ${ }^{12}$. Assim, buscaremos aqui explorar as conexões entre megaeventos, militarização e expansão das milícias nas áreas de "sombra", destacando, contudo, que essas áreas representam uma considerável parcela do território da cidade. Observando o mapa seguinte, é possível identificar a Zona Oeste como as áreas nomeadas como

\section{AP4 e AP5 à esquerda ${ }^{13}$ - e é possível observar que essa ocupa um território equivalente a mais do que a metade do mapa da cidade.}

${ }^{10} \mathrm{O}$ relatório final da Comissão Parlamentar de Inquérito encontra-se disponível on-line, no site do Núcleo de Estudos de Políticas Públicas em Direitos Humanos (NEPP-DH) da Universidade Federal do Rio de Janeiro: < http:/ / www.nepp-dh.ufrj.br/relatorio_milicia.pdf>. Acesso em: 20 dez. 2019.

${ }^{11}$ Cf. Disponível em: <https://noticias.uol.com.br/cotidiano/ultimas-noticias/2019/11/01/miliciado-rio-se-une-ao-trafico-para-enfraquecer-o-comando-vermelho.htm>. Cf. Acesso em: 20 dez. 2019. Disponível em: <https://odia.ig.com.br/rio-de-janeiro/2019/04/5633807-praca-seca--policiainvestiga-uniao--5-3.html\#foto=1>. Acesso em: $20 \mathrm{dez} .2019$.

12 Cabe ressaltar que as milícias não são exclusividade da Zona Oeste da cidade do Rio de Janeiro, sendo identificadas em 15 outros Estados brasileiros, segundo dado de 2018 do Ministério dos Direitos Humanos (Cf. Não é só no Rio. Milícias estão em 15 Estados de norte a sul do Brasil. Metrópole Disponível em: <https://www.metropoles.com/materias-especiais/nao-e-so-no-riomilicias-estao-em-15-estados-de-norte-a-sul-do-brasil>. Acesso em: <17 dez. 2019>). Contudo, é nesta região que sua atuação é mais frequente e reconhecida.

${ }^{13}$ A Zona Oeste, administrativamente, é composta pelas Áreas de Planejamento 4 e 5. Contudo, os indicadores socioeconômicos das duas regiões indicam grande disparidade entre elas, o que nos 


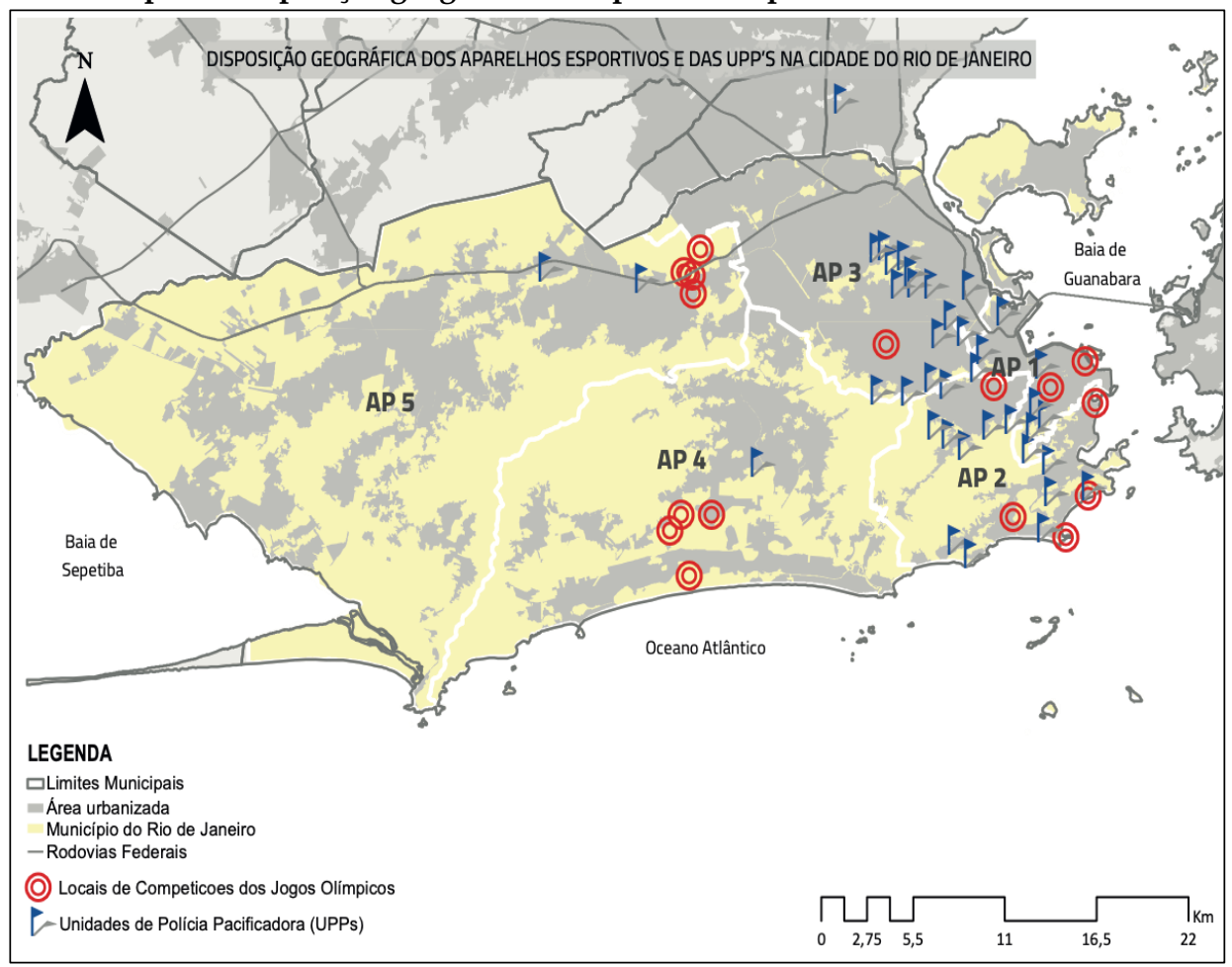

Fonte: Elaboração de Luciana Xavier (Ippur-UFRJ).

Dessa forma, neste artigo exploramos dados de campo e secundários visando identificar como se articulam militarização e megaeventos - dentro do recorte temporal dos últimos doze anos e do recorte territorial da cidade do Rio de Janeiro $^{14}$. Para tanto, organizamos o artigo em três partes. Na primeira, discutimos, a partir do caso do Rio de Janeiro e dialogando com parte da bibliografia pertinente, como tem se construído a militarização da vida a partir

permite concentrar nossos interesses de pesquisa na AP 5, mais pobre e mais vitimizada pelas milícias. Cf. Instituto Pereira Passos. Prefeitura da Cidade do Rio de Janeiro. Disponível em: <http://www.rio.rj.gov.br/dlstatic/10112/6165511/4162028/analise_idhm_rio_v4_compur.pdf>. Acesso em: 09 dez. 2019>.

${ }_{14} \mathrm{O}$ presente trabalho foi realizado com apoio do CNPq, Conselho Nacional de Desenvolvimento Científico e Tecnológico - Brasil (Processo 301637/2018-0) e da Fundação de Amparo à Pesquisa do Estado do Rio de Janeiro (Edital Jovem Cientista do Nosso Estado). O trabalho de campo foi realizado entre 2016 e 2018 especificamente nas localidades do Jardim Batan e da Vila Vintém, ambos na Zona Oeste da cidade. Aproveitamos para agradecer aos colegas do Cidades pela interlocução e a Luciana Ximenes (IPPUR-UFRJ) pelos lindos mapas. 
do desenvolvimento do projeto da Cidade Olímpica. Na segunda parte, descrevemos etnograficamente a diversidade de ordenamentos territoriais ${ }^{15}$ (LEITE, 2014, 2015) vigentes na Zona Oeste, visando demonstrar o que foi destinado ao "reverso" da Cidade Olímpica. Por fim, na conclusão, discutimos como "luz" e "sombra" se articulam dentro de um mesmo projeto de militarização da vida, que está hoje colocado para o governo dos pobres no Rio de Janeiro e no Brasil.

\section{0 Projeto da Cidade Olímpica e a militarização da vida}

Para discutir as conexões entre expansão das milícias, megaeventos e militarização, necessitamos, inicialmente, conceituar o que entendemos como militarização. Ainda que o debate sobre violência urbana e o papel desempenhado pelo estado e suas instituições militares não seja novo ${ }^{16}$, na última década diversas políticas, programas e iniciativas estatais indicam uma mudança qualitativa nessa atuação. Além do Programa de Pacificação de Favelas, analisado em outras oportunidades (ROCHA, 2018; DA MOTTA, 2017), é possível destacar: a ocupação das favelas do Alemão e da Maré pelo Exército Brasileiro, em 2010 e 2014, respectivamente; a realização de operações de Garantia da Lei e da Ordem (GLOs) ${ }^{17}$ durante os megaeventos, mas também em outras situações políticas específicas, como votações de medidas de austeridade na Assembleia Legislativa do Rio de Janeiro em 2017; a aprovação da Lei Antiterrorismo em março de 2016; e, por fim, a Intervenção Federal na área da segurança do Estado do Rio de Janeiro em 2018, sob gestão de militares do Exército Brasileiro.

\footnotetext{
${ }^{15}$ Segundo Leite (2017, p. 16-7), inspirada pela conceituação foucaultiana, a partir do projeto das Unidades de Polícia Pacificadora, a administração de territórios e populações pobres tem se dado de forma territorializada e articulando diferentes "poderes" - soberano, disciplinar e biopoder operados por agentes estatais e não estatais. Recombinados, esses elementos compõem diferentes "regimes territoriais", que se inscrevem de forma heterogênea nos territórios - dependendo de ajustes, negociações, resistências e confrontos determinados pela conjuntura. Seu foco de interesse são as favelas "pacificadas", mas aqui buscamos operar o conceito da autora para identificar a variedade de regimes territoriais em favelas "não pacificadas" também.

${ }^{16}$ Cf. Soares (1996); Misse (2006); Machado da Silva (2004), entre outros.

${ }_{17} \mathrm{O}$ dispositivo constitucional "Garantia da Lei e da Ordem" concede provisoriamente aos militares a faculdade de atuar com poder de polícia até que sejam superadas as condições que levaram ao seu acionamento. Esses seriam os "casos em que há o esgotamento das forças tradicionais de segurança pública, em graves situações de perturbação da ordem", segundo o site do Ministério da Defesa. Ainda segundo o Ministério, nessas ações as Forças Armadas agem de forma "episódica, em área restrita e por tempo limitado, com o objetivo de preservar a ordem pública, a integridade da população e garantir o funcionamento regular das instituições" (MINISTÉRIO DA DEFESA, 2019).
} 
O que conecta todos esses eventos é o aumento da aplicação de medidas consideradas tipicamente de guerra para a repressão do chamado crime comum e/ou repressão a manifestações políticas. Assim, dentro dessa "metáfora da guerra" (LEITE, 2000; 2015; 2017) atualizada, a ocupação militar do Complexo de favelas da Maré foi classificada pelo Exército como uma "guerra irregular"18. Da mesma forma, durante a Intervenção de 2018, os militares "registraram" moradores de favelas fazendo fotos de seus rostos e carteiras de identidade, ação legitimada pelo Gabinete da Intervenção como "procedimento feito regularmente, legal, cuja finalidade é agilizar a checagem de dados junto aos bancos de dados da Secretaria de Segurança ${ }^{19 "}$. Para as favelas ocupadas pelas forças de "pacificação", inaugurou-se o uso de drones e de câmeras de vigilância, fazendo da atividade de "monitorar", junto com "negociar" e "confrontar", as formas de governar a vida nas favelas "pacificadas", como conceitua Menezes (2018).

Assim, a partir do que estamos descrevendo aqui, compreendemos militarização como um dispositivo ${ }^{20}$ que combina atuações do tipo militar (podendo ser realizadas por agentes militares ou não) com a disseminação de uma doutrina securitária que reordena a vida social, transformando todos os espaços em potenciais "campos de batalha" e todo tipo de insurgência em ameaça à segurança. Dessa forma, essa abordagem tenta ampliar o conceito de militarização para além da atuação estrita das Forças Armadas na conformação da vida social (ou do "mundo não militar"), ainda que reconhecendo a importância desses atores no processo, como destaca Lutz (2018). Mas, nos tempos atuais, a militarização se caracteriza por ser operada por diversos atores e estar presente em diversas dimensões, como na reorganização do espaço urbano a partir da lógica da vigilância e repressão (GRAHAM, 2017), no modelo

\footnotetext{
${ }^{18}$ Segundo o comandante da Força de Pacificação, General Antônio Carlos de Souza, a ocupação da Maré (entre abril de 2014 e junho de 2015) "[é] um conflito moderno. Uma guerra irregular, sem fronteiras, com inimigo difuso. E o mais difícil é atuar no meio do povo, com as ruas cheias de gente" (MINISTÉRIO DA DEFESA, 2015).

${ }^{19}$ Cf. Folha de São Paulo: "Militares do Exército tiram foto e 'ficham' morador de favela no Rio". 23 de fevereiro de 2018. Disponível em:

<https://www1.folha.uol.com.br/cotidiano/2018/02/moradores-deixam-comunidades-aposserem-fotografados-em-acao-do-exercito.shtml>. Acesso em: $20 \mathrm{dez} .2019$.

${ }^{20}$ Inspiramo-nos no conceito foucaultiano de dispositivo (conforme apresentado em sua obra História da Sexualidade, vol. 1, 2017), com todas as suas indefinições. Sobretudo, na definição apresentada pelo autor em uma entrevista, na qual ele afirma que o dispositivo é "um conjunto decididamente heterogêneo que engloba discursos, instituições, organizações arquitetônicas, decisões regulamentares, leis, medidas administrativas, enunciados científicos, proposiçooes filosóficas, morais, filantrópicas. Em suma, o dito e o não dito são os elementos do dispositivo. O dispositivo é a rede que se pode tecer entre esses elementos" (FOUCAULT, 2000, p. 244).
} 
de ajuda humanitária para comunidades após desastres naturais (SHELLER, 2013), na organização de megaeventos (GAFFNEY, 2019), na indústria cultural e na arte (LEANDER, 2017) ${ }^{21}$, para destacar alguns.

No contexto do que chamamos de "ciclo dos megaeventos", o acionamento do dispositivo da militarização é fundamental: ele está presente desde a menção a um programa de "pacificação" das favelas na candidatura do Rio de Janeiro à sede dos Jogos Olímpicos22, passando pela ideia do "cinturão olímpico" assumida pelo discurso oficial ${ }^{23}$ até a certeza cortante de parte dos moradores de favelas atingidos pelo programa de que, com o fim dos megaeventos, o programa também acabaria ${ }^{24}$ (RIBEIRO; VILLAROUCA, 2018, p. 1163). O projeto das UPPs foi essencial para a inserção do Rio de Janeiro no mercado das cidades sede dos megaeventos (VAINER, 2011), e por isso o planejamento de ocupação das favelas seguiu o desenho do circuito turístico, primeiro atingindo as favelas do "cinturão olímpico" (DAVIES, 2017) - fundamentalmente o entorno do estádio do Maracanã e a Zona Sul25. A preocupação em garantir segurança para os espectadores da Copa do Mundo e dos Jogos Olímpicos nunca foi um objetivo disfarçado (PALERMO, 2013, p. 320), e provavelmente essa explícita correlação entre "pacificação" e megaeventos contribui para explicar por que o projeto foi recebido com desconfiança por parte dos moradores de favelas, "pacificadas" ou não (RIBEIRO; VILLAROUCA, 2018).

A bibliografia internacional sobre megaeventos também já identificava sua imbricação com os temas de segurança e militarização. Segundo Zimbalist (2015), desde os atentados de 11 de setembro de 2001, os gastos com segurança nos grandes eventos esportivos têm crescido de forma escalonada. Os Jogos

\footnotetext{
${ }^{21} \mathrm{O}$ debate sobre a militarização como categoria não nos impede de ponderar que, da perspectiva de quem experimenta a militarização a partir das margens, dos espaços periféricos e sob influência das dinâmicas orquestradas pelos países centrais, para nós está colocada uma questão anterior: em uma sociedade violenta, racista e desigual como a nossa, em que o Estado sempre governou através de seus braços armados (legal e ilegalmente), que novidade traz a categoria militarização? Todavia, propomos utilizar a categoria ainda que saibamos de suas limitações, inclusive buscando contribuir para atualizá-la.

22 Para um estudo mais aprofundado sobre o tema, ver artigo de Palermo (2013).

${ }^{23}$ Sobre o assunto, ver Davies (2017).

${ }^{24}$ Em survey realizado entre 2014 e 2016 em diversas favelas "pacificadas", Ribeiro e Villarouca (2018) constataram que $43,4 \%$ dos entrevistados acreditavam que a UPP iria acabar após as Olimpíadas (p. 1163).

${ }^{25}$ A região da Zona Sul concentra a maior parte dos hotéis da cidade, ainda que tenha sido na Barra da Tijuca a maioria dos novos hotéis construídos (Cf. Revista Exame. Rio: hotel demais, hóspede de menos. 28 de Novembro de 2016. Disponível em: <https://exame.abril.com.br/negocios/rio-hotelde-mais-hospede-de-menos/>. Acesso em: $06 \mathrm{dez}$. 2019).
} 
Olímpicos de Verão de Atenas (2004), que foi o primeiro grande evento após os atentados, tinha uma previsão de gastos com segurança de U\$ 400 milhões, mas teve como gasto real U\$ 1,5 bilhão. Os gastos hoje variam entre U\$ 1 bilhão e U\$ 2 bilhões (2015: 100-1). Também para Giulianotti e Klauser (2010), o crescimento da participação da segurança no orçamento dos megaeventos é parte do fenômeno da "guerra ao terror", iniciada a partir dos atentados de 11 de setembro de 2001 nos Estados Unidos (2010: 3).

Analisando o caso brasileiro, Zimbalist (2015) argumenta que os protestos realizados durante a Copa das Confederações, em 2013, levaram o governo brasileiro a tomar medidas drásticas para impedir novos protestos durante a Copa do Mundo de Futebol de 2014, como o aumento do pessoal contratado para fazer a segurança e o investimento em tecnologia de vigilância (ZIMBALIST, 2015 , p. 245). No mesmo sentido, Gaffney (2013) também identifica os protestos realizados durante a Copa das Confederações de 2013 como um momento de inflexão para o governo brasileiro no sentido de aumentar o contingente de pessoas e tecnologias envolvido nos megaeventos. $\mathrm{O}$ autor chama ainda atenção para como não foi observada durante os Jogos Pan-Americanos de 2007 a mesma preocupação que houve com as manifestações políticas. Nessa ocasião, as atenções teriam se voltado para o controle ostensivo do espaço público, a ocupação de favelas e a circulação de pessoas ligadas ao evento. Ao comentar como os orçamentos para segurança dos megaeventos sempre "estouram", Gaffney (2013) ainda afirma que outra característica importante desse tipo de evento é que nunca há prestação de contas sobre os gastos, e que, ainda que não tenha havido ameaças à realização do evento, a necessidade do aumento no orçamento não costuma ser questionada. Observamos, assim, mais um papel a ser cumprido pela repressão às manifestações políticas.

Assim, ainda que seja compreensível que esse tipo de evento demande um aparato de segurança elevado pelo contingente de pessoas que recebe, é notável que no Rio de Janeiro, especificamente, esse aparato tenha sido acionado para garantir remoções nas favelas e outras áreas populares (MAGALHÃES, 2013), para reprimir protestos contra o aumento no custo de vida nas cidades (MAIA; ROCHA, 2014), para ocupar territórios e permitir a reconfiguração da cidade, modificação necessária para que esta se tornasse apta a participar do circuito internacional de "cidades-mercadorias" (VAINER, 2011). Mas, como queremos demonstrar aqui, o processo de militarização identificado e analisado pelas pesquisas já mencionadas possui um reverso, que ocorreu e ocorre na "regiãosombra" da Zona Oeste. Na próxima seção nos propomos a jogar luz sobre esse contexto. 


\section{A sombra da Cidade Olímpica: a Zona Oeste}

A população da Zona Oeste, segundo o Censo de 2010, representa 41,36\% (2.614.728 pessoas) de toda a capital fluminense (6.320.446 habitantes). Como podemos observar no Mapa 2, a seguir, a região representa mais de 1/3 do território da cidade. Ainda assim, a Zona Oeste está cristalizada no imaginário popular como um local distante, pouco desenvolvido, rural, afastada de tudo (FERNANDES, 2011; SIQUEIRA, 2013; DAVIES, 2017; DE OLIVEIRA, 2017). Da mesma forma, ela é representada de forma homogênea, desconsiderando suas diferenças internas ${ }^{26}$. Essa representação, estigmatizada e redutora, está apartada da imagem divulgada e comercializada do Rio de Janeiro, restrita às praias e aos pontos turísticos localizados nas áreas nobres (FREIRE-MEDEIROS, 2005). Da mesma forma, nas imagens publicizadas do Rio Olímpico, “(...) são potencializadas imagens-síntese da cidade [enquanto] outras leituras e imagens da cidade se encontram veladas, sem nenhuma menção" (SANCHÉZ; GOMEZ; GUTERMAN, 2013, p. 4). Nessa conformação, a Zona Oeste é a área apagada, velada, à sombra.

Assim, nesta seção, realizamos um mergulho etnográfico na região, tendo como referência o trajeto do trem que parte da região central da cidade e segue para a Zona Oeste, meio de transporte preferencial (às vezes único) de centenas de milhares de trabalhadores ${ }^{27}$ que diariamente vão à região central. Seguindo o percurso do trem, afastamo-nos paulatinamente da região mais rica da cidade,

${ }^{26}$ Como já mencionado, a Zona Oeste é formalmente subdividida em duas áreas, nomeadas pela prefeitura como Área de Planejamento 4 e 5. Porém, esse trabalho opta por referenciar como 'Zona Oeste' somente a Área de Planejamento 5, pois essa classificação, mais do que uma categoria geopolítica, é uma categoria sociocultural expressa pelo lugar de classe de seus moradores. Como aponta Maria de Oliveira (2017): “Localizada no extremo oeste do Município do Rio de Janeiro, a AP5 possui uma extensão territorial de $592,33 \mathrm{~km} 2$, correspondente a quase metade do território da Cidade $(48,4 \%)$. Habitualmente chamada de Zona Oeste, apesar de, a rigor, geograficamente, a Zona Oeste também incluir as regiões da AP4, a denominação passou, pelo uso popular, a identificar somente a AP5 e alguns bairros da AP4, com características sócio-econômicas parecidas a da AP5. Esta imprecisão na nomenclatura é resultado da estreita relação entre a localização espacial e nível social, uma característica da Cidade do Rio de Janeiro, onde descrições geográficas são generalizadas e confundidas com caracterização social. Neste amplo espaço de planícies e morros, os núcleos urbanos se adensaram em torno de estações ferroviárias, alguns tão distantes do Centro da Cidade, como Campo Grande e Santa Cruz, que chegam a $70 \mathrm{~km}$ de distância, que se apresentam como se fossem 'outras cidades' ou cidades satélites" (DE OLIVEIRA, 2017, p. 325).

${ }^{27}$ Cf. Jornal O Globo. "Central do Brasil: a estação que busca um novo destino para sair da crise”, 29 de Julho de 2018. Disponível em: <https://oglobo.globo.com/rio/central-do-brasil-estacao-quebusca-um-novo-destino-para-sair-da-crise-

22929594\#: :targetText=A\%20Central\%20\%C3\%A9\%20um\%20mundo,cruzam\%20diariamente\%20s uas\%20plataformas\%20centen\%C3\%A1rias.>. Acesso em: 20 dez. 2019. 
de suas praias e de seus moradores - do Rio de Janeiro que se quer apresentar e vender. Da estação central do Brasil à última estação da linha que serve à Zona Oeste, o trajeto costuma ser percorrido em 80 minutos.

Nossa viagem começa pelo centro da cidade. Localizada no coração da cidade do Rio de Janeiro, a centenária estação de trem chamada Central do Brasil é uma das mais antigas do país. Das diferentes linhas que saem da Central do Brasil destacam-se Japeri, Santa Cruz, Saracurana e Belford Roxo. O ramal Santa Cruz é o que serve à Zona Oeste, e é ele que vamos percorrer

\section{Mapa 2 - Trajeto do trem que percorre o Ramal Santa Cruz, saindo da Estação Central} do Brasil em direção à Zona Oeste.

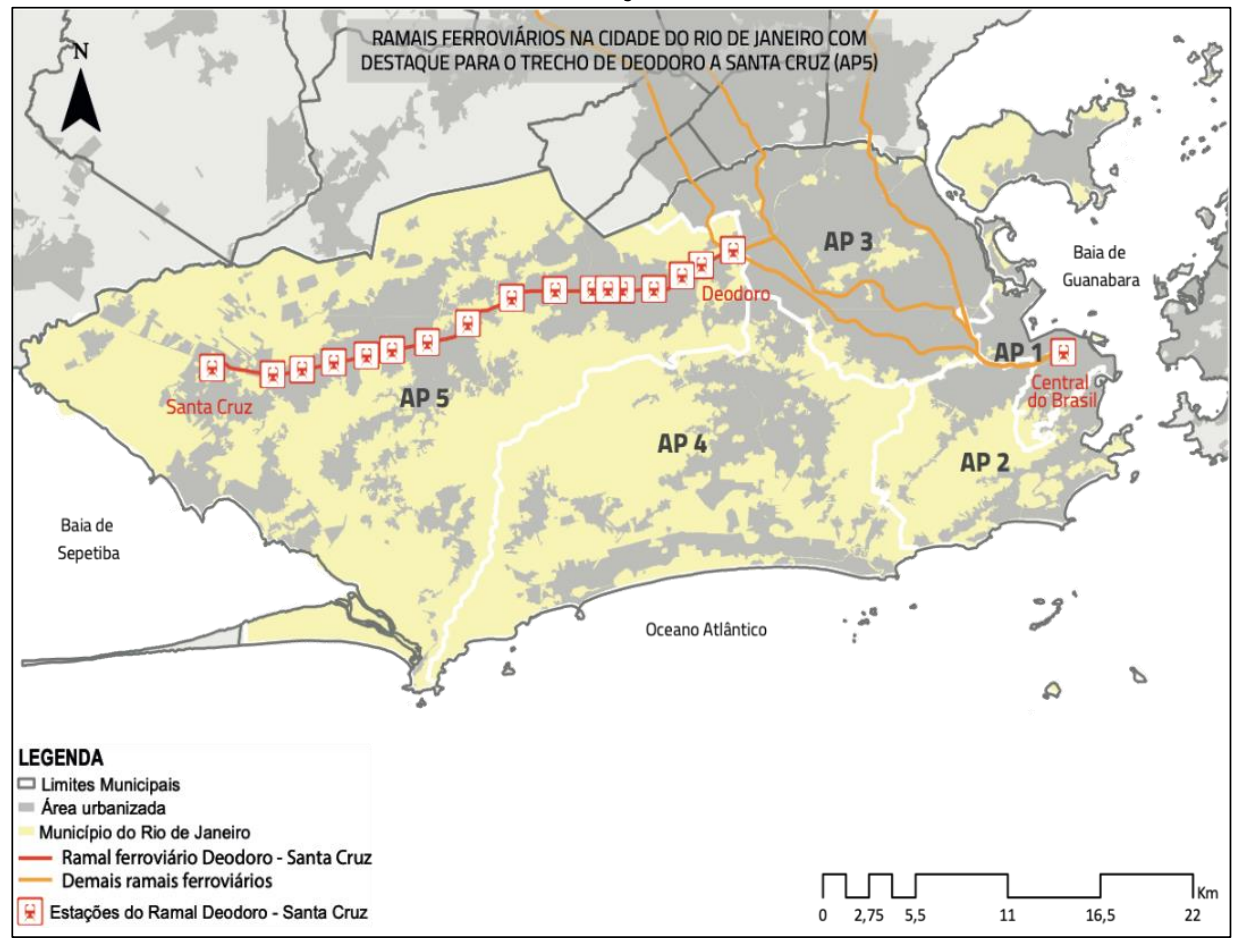

Fonte: Elaboração de Luciana Xavier (Ippur-UFRJ).

Partimos da Central do Brasil. No horário de pico, um amontoado de pessoas se aglutinam junto às portas do trem que para lentamente na plataforma. Em questão de segundos, um empurra-empurra generalizado toma conta, os mais corajosos se lançando à frente na disputa por um lugar. Ao abrir das portas, as pessoas literalmente se jogam para conseguir um lugar, imagem que lembra um vulcão em erupção. Os vencedores dessa disputa ganham o direito de viajarem 
sentados depois de um dia inteiro de trabalho. Os que não conseguem lugar para sentar deslocam-se para as partes mais vazias do trem, normalmente as extremidades dos vagões.

A primeira estação dessa linha, quando o trem chega à Zona Oeste, é Deodoro, linha de transferência para outras áreas da cidade, como a Baixada Fluminense. A combinação entre o cinza metalizado da estação - revitalizada em 2016 para os Jogos Olímpicos -, o verde das árvores dos quartéis no entorno e o profundo silêncio desse pacato bairro saltam aos olhos. Também é possível observar na paisagem muitos quartéis e poucas casas. A presença dos militares também é sentida no controle das principais ruas do bairro, onde eles fazem patrulhamento. Nos últimos anos, o bairro teve relativa notoriedade midiática por ser um dos locais que abrigaram equipamentos esportivos para os Jogos Olímpicos de 2016, configurando-se assim como uma "região olímpica" (DAVIES, 2017).

A Vila Militar é a próxima estação na qual o trem faz parada obrigatória. Como o próprio nome elucida, esse bairro também carrega uma grande herança histórica militar. Se Deodoro é um bairro que abriga muitos quartéis, Vila Militar é um bairro que abriga as habitações desses militares. Assim como seu vizinho, essa estação também foi revitalizada para os Jogos Olímpicos, ganhando uma área coberta metalizada que não existia anteriormente. A estação combina um certo ar moderno (a partir da revitalização) e um lado tradicional com a construção arquitetônica de um pequeno castelo que existe dentro da estação, de cor bege com detalhes em vermelho. O bairro também é pacato, apesar das diversas casas que existem em volta e o verde das árvores e dos morros próximos que configuram essa paisagem.

A estação de Magalhães Bastos é a primeira a romper com a calmaria dos bairros anteriores. Ela foi a última a ser reformada, segue os mesmos padrões das outras, e a partir dela é possível ver as marcas urbanas dos Jogos Olímpicos contrastando com os símbolos da gestão local do tráfico de drogas a varejo. Ao olhar para o lado esquerdo, é possível ver a estação do BRT28 que tem o mesmo nome do bairro. Em frente, é possível avistar a via expressa TransOlímpica ${ }^{29}$. O bairro, a partir das obras de mobilidade urbana, configurou-se como ponto de encontro entre os moradores da Zona Oeste (Deodoro - Santa Cruz) e a região da Barra da Tijuca e Jacarepaguá - região essa que ganhou importante centralidade na cidade. Essa via expressa facilita o deslocamento, encurtando a distância entre

${ }^{28}$ O Bus Rapid Transit (BRT) é um modelo de transporte urbano iniciado em 2012 no Rio de Janeiro em preparação para os Jogos Olímpicos de 2016.

${ }^{29}$ TransOlímpica é uma via expressa inaugurada em 2016 com o objetivo de ligar as duas partes da Zona Oeste à Barra da Tijuca com a região olímpica de Deodoro. 
essas duas regiões, promovendo uma diminuição no tempo de percurso de cerca de 30 minutos. No deslocamento do trem é possível ver, às margens do trilho, a paisagem trocar de cor, abandonando o verde das áreas arborizadas e assumindo o laranja do tijolo das casas sem embolso. Ainda nas linhas do trem é possível perceber um espaço aterrado, sem vegetação, com muros pintados de branco, com bancos espalhados, luzes ao redor, fendas abertas para passagem de pedestre por dentro da estação (mesmo havendo passarela próxima); muitas dessas passagens são vigiadas por menores de idade que portam armas de fogo e rádio transmissor. Esse espaço da linha férrea se tornou um lugar de sociabilidade de usuários e não usuário de drogas. Entre os muros dessa estação e da seguinte cresce uma favela, território de atuação de uma quadrilha de traficantes de drogas.

Realengo é um dos bairros mais densos e complexos da cidade. Sua estação, ao contrário das anteriores, não foi reformada. Ela tem um aspecto antigo, com pintura envelhecida e poucos espaços cobertos. A paisagem ao redor destaca o contraste entre dois mundos. Do lado esquerdo é possível ver a Praça do Canhão, herança militar do bairro que já abrigou a fábrica de cartucho e abriga a Escola de Instrução Especializada do Exército. Do lado direito, vê-se a favela Vila Vintém, cuja paisagem é marcada por casas pequenas e médias, a maioria ainda no tijolo, sem pintura. No deslocamento do trem para a próxima estação esse contraste vai ficando mais evidente: de um lado, a "ordem" do mundo militar; do outro, o "caos" representado pela favela. Lado a lado, tendo apenas os trilhos do trem para separá-los. O bairro é marcado por disputas territoriais entre diferentes grupos armados, de facções de traficantes de drogas às milícias. Ainda em Realengo encontra-se a favela do Batan, conhecida em função da tortura dos jornalistas do Jornal O Dia por milicianos da região. Essa favela exemplifica a fluidez dos diferentes regimes de cerceamento a que estão submetidos os moradores de favelas: em menos de dez anos, o Batan foi dominado por traficantes de drogas, em seguida, por um grupo de milicianos, depois foi ocupado pela Polícia Militar de Pacificação, de novo foi ocupado por traficantes de drogas e, no momento, está dominada por um grupo de milicianos em aliança com outra facção de traficantes.

A estação seguinte, Padre Miguel, é sede da escola de samba Mocidade Independente, uma das mais importantes do carnaval carioca - e por isso a paisagem das construções é dominada pelo verde, cor da escola. Da própria estação é possível ver a quadra antiga, assim como a comunidade onde ela nasce, a Vila Vintém - que se divide entre dois bairros, Realengo e Padre Miguel. Nessa localidade, atua há muitos anos uma facção do tráfico de drogas, e ela é 
considerada o local onde essa facção nasceu e também seu quartel-general. Porém, nos últimos meses os moradores do bairro vivem sob grande apreensão, em função da possível ocupação do local por grupos paramilitares de milicianos com o apoio de uma facção rival. No deslocamento do trem entre as estações de Padre Miguel e Guilherme da Silveira é possível avistar, na linha férrea, locais onde pessoas se reúnem para fazer uso de drogas ilícitas, particularmente o crack, e também um local para venda de bebidas.

Bangu é conhecido popularmente pelo calor intenso e por ter duas estações de trem: Guilherme da Silveira e Bangu. A principal e mais populosa é a estação de Bangu, cujo aspecto envelhecido contrasta com o entorno do bairro e seu dinamismo econômico. Da estação é possível avistar o shopping construído na antiga fábrica de tecido que deu nome ao bairro e fez com que a área fosse ocupada no início do século XX. Além disso, na estação também é possível avistar o famoso "calçadão de Bangu" - uma rua de passagem de pedestre aglutinada por um comércio vigoroso e diversificado -, quase sempre cheio de transeuntes e ambulantes vendendo os mais variados produtos. Por ser um importante centro local, com vasto comércio formal e informal, a região foi palco recente de diversos confrontos entre comerciantes ambulantes e o poder público, que vem realizando por toda a cidade operações chamadas de "Choque de Ordem".

Bangu, assim como Realengo, concentra diferentes tipos de ordenamentos territoriais. Vila Kennedy, Vila Aliança, Jardim Bangu e Catiri são conjuntos habitacionais construídos na região durante a década de 1960, momento marcado pelas políticas de remoção de favelas realizadas pelos governos militares. Vila Kennedy é um território controlado por uma facção de traficantes de drogas, e ali foi instalada a última Unidade de Polícia Pacificadora, em 2014. Em 2017, foi cenário para diversas operações policiais realizadas no âmbito da Intervenção Federal na Segurança do Rio de Janeiro, e mais recentemente tem sofrido com ataques de grupos de milicianos. A localidade de Vila Aliança, vizinha da Vila Kennedy, é controlada por uma facção de traficantes que tem se aliado em diversos locais a grupos de milicianos. Já os outros dois conjuntos são controlados por grupos de milicianos locais.

Senador Camará e Santíssimo, apesar de serem bairros distintos, compartilham de algumas características. Suas estações de trem são parecidas tanto do ponto de vista arquitetônico quanto da ausência de conservação. Esses dois bairros podem ser considerados o último reduto do tráfico de drogas a varejo na Zona Oeste, e são majoritariamente dominados pela mesma facção de traficantes de drogas, que tem se aliados aos grupos paramilitares. Assim, a região tem desfrutado de certa "tranquilidade" nos últimos anos, em função da 
ausência de conflitos característicos das disputas territoriais entre grupos armados.

Campo Grande, o bairro mais populoso da Zona Oeste, tem a maior quantidade de estações de trem por bairro: Augusto Vasconcelos, Campo Grande e Benjamim do Monte. Sua estação principal é uma das maiores estações de trem da região e, nitidamente, mais bem conservada que as anteriores. O entorno é sempre muito movimentado pelo fato de ser um centro comercial, disputando com Bangu o título de maior comércio da Zona Oeste. O bairro também tem uma estação do BRT que o conecta à região da Barra da Tijuca, "legado" dos Jogos Olímpicos de 2016. Porém, menos de dois anos depois do fim dos Jogos, os trechos que serviam à população de Campo Grande foram fechados, com a justificativa - dada pela empresa que geria o serviço público em forma de consórcio - de que faltaria segurança no local para operar as linhas ${ }^{30}$.

O bairro é um dos maiores territórios de operação da milícia, que nos últimos anos conseguiu tomar essas localidades dos traficantes de drogas que antes operavam na região. Ali se evidencia como milícia e forças militares oficiais atuam de forma articulada. No caso, o $30^{\circ}$ Batalhão da Polícia Militar (que atua no local) realizou frequentes operações policiais de confronto com os traficantes de drogas, ações que antecederam a ocupação pelas milícias. Entre os moradores, é sabido que muitos policiais militares lotados nesse batalhão atuam também nos grupos milicianos ${ }^{31}$.

Inhoaíba, Cosmos e Paciência são bairros pequenos, menos populosos que seus vizinhos. Seus moradores normalmente precisam se deslocar até Campo Grande ou Santa Cruz para terem acesso a certos serviços como hospitais, cartório, comércio etc. As três localidades também são consideradas o berço da milícia na Zona Oeste, já que dali vem o maior grupo paramilitar do Estado. Este grupo, chamado Liga da Justiça, é caracterizado pela imprensa especializada como formado por ex-traficantes que foram "cooptados" pelos milicianos e chegaram a posições de chefia dentro da organização ${ }^{32}$. Provavelmente por

${ }^{30}$ Cf. G1 Site de Notícias. "Fechamento de Estações do BRT na Zona Oeste aumenta superlotação". 25 de Junho de 2018. Disponível em: <https://g1.globo.com/rj/rio-de-janeiro/noticia/fechamentode-estacoes-do-brt-na-zona-oeste-aumenta-superlotacao-e-passageiros-tem-que-pegar-maisonibus.ghtml>. Acesso em: 02 dez. 2019.

${ }^{31}$ Cf. Notícias Uol. RJ investiga policiais suspeitos de atuar como agentes duplos para as milícias. 27 de fevereiro de 2019. Disponível em: <https://noticias.uol.com.br/cotidiano/ultimasnoticias/2019/02/27/rj-investiga-policiais-suspeitos-de-atuar-como-agentes-duplos-paramilicias.htm>. Acesso em: 02 dez. 2019.

32 Cf. O Globo. "Narcomilícias: traficantes e milicianos se unem em 180 áreas do Rio, segundo investigação". 10 de Outubro de 2019. Disponível em:

$<$ https://oglobo.globo.com/rio/narcomilicias-traficantes-milicianos-se-unem-em-180-areas-do-rio- 
influência dessas lideranças, esse grupo especificamente tem apostado na venda de drogas ilícitas nas localidades que controla - por isso tem sido caracterizado pela imprensa como uma "narcomilícia". Se antes a interdição ao comércio de drogas ilícitas era uma das principais características das milícias, hoje muitos desses grupos exploram essa vantajosa atividade comercial, assim como exploram todas as outras atividades econômicas encontradas nessas localidades. Da mesma forma, esse mesmo grupo de milicianos protagoniza a aliança com uma facção de traficantes de drogas. Juntos, iniciaram uma grande disputa armada por territórios com a maior e mais antiga faç̧ão do estado, o Comando Vermelho.

Finalmente, chegamos à última parada do ramal da Zona Oeste, o bairro de Santa Cruz, que também tem duas estações em seu perímetro: Tancredo Neves e Santa Cruz. Do ponto de vista estético e arquitetônico elas são semelhantes, mas possuem histórias e paisagens sociais bastante distintas. Enquanto a estação de Santa Cruz localiza-se em território de atuação já antiga de grupos de milicianos, a estação de Tancredo Neves é localizada ao lado da favela do Antares, onde há muito tempo atuam quadrilhas de traficantes de drogas. Vizinhas à favela do Antares temos outras duas favelas que são área de atuação das quadrilhas de traficantes, mas que mais recentemente têm sido alvo de operações policiais. Como a experiência de outras localidades indica, o efeito dessas ações costuma ser o enfraquecimento das quadrilhas de traficantes locais e, posteriormente, a invasão das localidades por grupos de milicianos. Contudo, com o surgimento das "narcomilícias", mencionadas anteriormente, tornou-se mais comum que membros de quadrilhas de traficantes de drogas sejam incorporados aos grupos de milicianos - o que foi nomeado pelos moradores da região entrevistados pela pesquisa "pula-pula".

Como efeito dessas movimentações mais recentes nas dinâmicas sociais dos grupos armados na cidade, observa-se o aumento dos confrontos entre grupos e faç̧ões (HIRATA; GRILLO, 2019). Cotidianamente registram-se confrontos e contam-se vítimas, o que até recentemente não era comum acontecer em áreas controladas pelas milícias. Pelo contrário, a forma de gestão territorial característica das milícias é (ou era) a ausência de confronto (CANO; DUARTE, 2012) - especialmente porque nos locais onde atua a milícia são quase inexistentes as operações policiais ${ }^{33}$. Possivelmente a maior evidência dessa

segundo-investigacao-24007664>. Acesso em: 20 dez. 2019.

${ }^{33}$ Levantamentos sobre confrontos armados com mortos indicaram que, se tem aumentado o número de mortos pela polícia, não foram identificados confrontos em áreas de atuação das milícias. Cf. Polícias mataram 881 pessoas em 6 meses no RJ, nenhuma em área de milícia. Disponível em: 
mudança é o aumento no número de mortes na cidade a partir de $2013^{34}$, com destaque para o aumento na letalidade em ações policiais (que aumentou 56\% em relação a 2018, segundo RAMOS, 2019) ${ }^{35}$.

Tendo como fio conector o percurso feito pelo trem urbano pela Zona Oeste, tentamos nessa seção descrever parte dos fenômenos expressos nesses números. Buscamos, de forma panorâmica, apresentar a variedade de composições entre poder público, crime, quadrilhas de traficantes de drogas no varejo, grupos paramilitares e outros poderes locais. Em termos cotidianos, para além das variações locais, morar em uma área "de milícia" significa, de forma imediata, que as possibilidades de acesso a serviços que deveriam ser públicos - do transporte, habitação, segurança até gás, internet e televisão à cabo - serão necessariamente mediados por agentes privados, sob risco de coação e represálias severas para quem se recusar. Da mesma forma, a função de fiscalização da prestação desses serviços que o poder público deveria realizar também será impedida pela coação dos grupos armados, como no caso das construções na região do Muzema que desabaram em 201936.

Assim, as milícias operam uma forma de controle social de alta intensidade sobre a vida cotidiana das pessoas que moram nessas áreas, inclusive com repercussões para a vida política e associativa local, abafando qualquer resistência coletiva. Recuperando o conceito de regime territorial tal qual proposto por Leite (2017 e Cf. nota de rodapé 13), compreendemos que as milícias oferecem, elas também, um modelo de governo dos pobres que atua de forma territorializada e combina elementos de disciplina, tutela e vigilância com

<https://noticias.uol.com.br/cotidiano/ultimas-noticias/2019/08/20/policias-mataram-881pessoas-em-6-meses-no-rj-nenhuma-em-area-de-milicia.htm>. Acesso em: 02 dez. 2019.

${ }^{34}$ Segundo dados do Instituto de Segurança Pública do Estado do Rio de Janeiro, se em 2012 alcançouse a menor taxa de homicídios desde o começo da série histórica (28,7 homicídios por 100 mil habitantes, e a série começa em 1991 com 60,3 homicídios/100 mil habitantes), em 2018 tivemos 39,4 homicídios/100 mil habitantes. Cf. ISP (2019).

${ }^{35}$ Está na agenda de pesquisa investigar o impacto dos confrontos em áreas de milícias sobre a legitimação social que esses grupos costumavam desfrutar entre os moradores das áreas onde atuavam (CANO; DUARTE, 2012), considerando que a fonte dessa legitimação viria, substancialmente, do principal "serviço" comercializado pelas milícias, que é a segurança - ou a "tranquilidade", em linguagem nativa (ARAUJO SILVA, 2017).

${ }^{36}$ No caso do Muzema, chamou a atenção da opinião pública que prédios de vários andares tenham sido construídos sem qualquer autorização da prefeitura. Os fiscais da prefeitura, no entanto, declararam ter medo de fiscalizar obras em "áreas de milícias". Cf. https://oglobo.globo.com/rio/prefeitura-diz-que-fiscais-temem-reacao-da-milicia-na-muzemaoperacoes-terao-apoio-da-policia-militar-23599526. Os fiscais denunciaram ainda que, mesmo quando emitem parecer para embargar as obras, esses não são cumpridos por "pressão política" dos milicianos. Cf. https://oglobo.globo.com/rio/nao-aguento-mais-embargar-nao-acontecer-nada-dizfuncionario-da-prefeitura-sobre-fiscalizacao-na-muzema-23596048. Acesso em: 02 dez. 2019. 
repressão, violência e eliminação física. Assim, pensadas em conjunto com outras modalidades de controle social armado, as milícias participam do mosaico de regimes territoriais que compõem a cidade (vale a pena destacar que mesmo dentro da Zona Oeste encontramos diferentes regimes territoriais, considerando a contiguidade entre áreas dominadas por milícias e por quadrilhas de traficantes de drogas).

Na próxima e última seção, discutimos como regimes territoriais articulam-se com militarização e com megaeventos.

\section{Considerações finais: qual o legado dos megaeventos para o Rio de Janeiro?}

Giulianotti e Klauser (2010) elencam seis itens do que chamam de legado securitário ("security legacy") dos megaeventos esportivos: novas tecnologias de segurança; novas práticas securitárias; políticas públicas e nova legislação de segurança; transformações sociais impostas externamente (por exemplo, a remoção de populações consideradas indesejadas de locais disputados); mudanças generalizadas nas relações sociais e transocietais (como alterações nas relações entre moradores de uma localidade e a polícia); e reconfiguração (redevelopment) urbana (GIULIANOTTI; KLAUSER, 2010, p. 5-6). Considerando o caso do Rio de Janeiro, observamos a repetição de padrões em outros casos pelo mundo, que reforçam a conexão entre a inserção dessas cidades no circuito das cidades-mercadoria e do fluxo internacional de acumulação urbana (RIBEIRO; SANTOS Jr., 2013) e o aumento da militarização. Buscamos demonstrar aqui que esse aumento da militarização se deu nos territórios de pobreza, através do Programa de Pacificação de Favelas ${ }^{37}$, mas não apenas, ocorrendo também de forma pulverizada no resto da cidade, no contexto de vigilância e repressão ocasionados pelos megaeventos. E é nesse contexto que incluímos, também, a expansão das milícias.

\footnotetext{
${ }^{37} \mathrm{O}$ fato de hoje o Programa de Pacificação de Favelas estar em extinção não aparenta modificar o cenário. A "crise das UPPs" como tema de debate público começa a emergir já em 2013, no contexto da denúncia do desaparecimento do pedreiro e morador de uma favela "pacificada" Amarildo (ROCHA, 2016; FRANCO, 2018). Ainda assim, Leite (2017) argumenta que as UPPs foram "bemsucedidas" no sentido de produzir três importantes efeitos: generalizar e nacionalizar o projeto de ocupação militar de áreas pobres para outras áreas do Brasil e do mundo; envolver diretamente empresas na execução de programas públicas; e, por fim, estimular uma tecnologia de poder considerada eficaz para o governo dos territórios pobres. Tais efeitos, articulados, permitiram a expansão de interesses econômicos de empresas privadas nessas localidades. Para além de debates sobre o sucesso ou fracasso do programa, interessa-nos pensar como este contribuiu para expandir o controle militarizado de territórios e populações (LEITE, 2017; MENEZES, 2018; ROCHA, 2018).
} 
A alegoria do bumerangue, acionada por Foucault em "Em defesa da Sociedade" (FOUCAULT, 2003 [1997], p. 103), é utilizada por diversos autores (JENSEN, 2016; GRAHAM, 2012; WALL, 2013) para ilustrar como técnicas, tecnologias e práticas securitárias circulam entre (ex) colônias e (ex) metrópoles, fazendo das primeiras um campo de experimentação e teste para o que será posteriormente - e com variações - aplicado nas segundas. Desde helicópteros utilizados no Vietnã e depois no patrulhamento das ruas de Los Angeles a veículos do tipo SUV que se assemelham a tanques, passando pelos drones, os autores chamam atenção para o fato de que tais formas de controle são primeiro experimentadas nos países colonizados para depois serem devolvidas (daí a óbvia analogia com o bumerangue) aos países centrais, para serem utilizadas contra as populações nacionais (WALL, 2013, p. 34). Assim, ainda que considerando tal circulação com apenas uma direção, os autores partem da constatação de que tais tecnologias de controle e vigilância assumem formas diferentes em cada uma de suas versões nacionais, com adaptações e atualizações feitas em cada contexto.

Neste sentido, é fundamental compreender quais adaptações e atualizações são feitas no contexto brasileiro e do Rio de Janeiro, e como se configura, portanto, nossa versão nacional da militarização. Por aqui, analisar os fenômenos mais recentes a partir da chave da militarização precisa considerar que há quase vinte anos utiliza-se no patrulhamento das favelas cariocas um carro blindado adaptado para uso militar apelidado de Caveirão ${ }^{38}$, bem como helicópteros, fuzis e outros armamentos considerados de uso em situações de guerra. Precisa considerar ainda que os policiais que patrulham nossas ruas e bairros são policiais militares, formados na lógica da guerra - e são esses mesmos policiais militares que formam as hostes que compõem os grupos de milicianos. Compreender como militarização e "milicialização" estão articuladas - como em um "jogo de luz e sombras" - é hoje tema incontornável para identificar as formas de controle, disciplinamento e repressão colocadas à disposição para o governo dos pobres em uma cidade (e um país) cada vez mais desigual, empobrecido e violento.

\footnotetext{
${ }^{38}$ Cf. Anistia Internacional, 2006. Vale ressaltar ainda que há quase quinze anos diversas organizações de defesa dos direitos humanos denunciam violações causadas pelo uso deste tanque, inclusive para intimidação da população local. Ver também Magalhães (2007).
} 


\section{Referências}

ALVES, José Carlos Silva.

(2008). Milícias: mudanças na economia política do crime no Rio de Janeiro". In: Justiça Global (comp.). Segurança, tráfico e milícias no Rio de Janeir. Rio de Janeiro, Brasil: Fundação Heinrich Böll, pp. 33-36.

\section{ANISTIA INTERNACIONAL.}

(2006). "Vim buscar sua alma": o caveirão e o policiamento no Rio de Janeiro. Disponível em: <http://www.dhnet.org.br/dados/relatorios/a _pdf/r_ai_caveirao.pdf>. Acesso em: 21 jan. 2020.

ARAUJ0 SILVA, Marcella.

(2017). Houses, tranquility and progress in an "área de milícia'. Vibrant - Virtual Brazilian Anthropology, v. 14, n. 3, pp. 1-17.

\section{ASSOCIATED PRESS.}

(2017). Rio Olympic planning assailed for 'white elephant' venues. CBC News 23 de Maio de 2017. Disponivel em: <https://www.cbc.ca/sports/olympics/rio-dejaneiro-white-elephants-1.4127305>. Acesso em: 09 abr. 2019.

BARROS, Rachel.

(2016). Urbanização e "pacificação" em Manguinhos: Um olhar etnográfico sobre sociabilidade e ações de governo. Tese de Doutorado. Instituto de Estudos Sociais e Políticos.

BURGOS, Marcelo Baumann.

(2002). A utopia da comunidade: Rio das Pedras, uma favela carioca. Edicoes Loyola.

CANO, Ignacio; IOTT, Caroline.

(2008). Seis por meia dúzia. In: Justiça Global (Comp). Segurança, tráfico e milícias no Rio de Janeiro. Rio de Janeiro, Brasil: Fundação Heinrich Böll, pp. 51-74.

CANO, Ignacio; DUARTE, Tais.

(2012). No sapatinho: a evolução das milícias no Rio de Janeiro (2008-2011). Rio de Janeiro, Brasil: Laboratório de Análise da Violência (LAVUERJ).
CARVALH0, Monique Batista.

(2014). Os dilemas da "pacificação": práticas de controle e disciplinarização na "gestão da paz" em uma favela no Rio de Janeiro. Tese de Doutorado. Programa de Pós-Graduação em Ciências Sociais da Universidade do Estado do Rio de Janeiro.

\section{COMITÊ POPULAR DA COPA E OLIMPÍADAS DO RIO DE} JANEIRO.

(2013). Megaeventos e Violações dos Direitos Humanos no Rio de Janeiro. Dossiê, Rio de Janeiro, Maio, 2013. Disponível em: <https://comitepopulario.files.wordpress.com/ 2012/04/dossic3aa-megaeventos-eviolac3a7c3b5es-dos-direitos-humanos-no-riode-janeiro.pdf>. Acesso em: 20 nov. 2019.

DAM0, Arlei Sander; OLIVEN, Ruben George.

(2013). 0 Brasil no horizonte dos megaeventos esportivos de 2014 e 2016. sua cara, seus sócios e seus negócios. Horizontes antropológicos, $\mathrm{n}$. 40, pp. 19-63.

DA MOTTA, Jonathan.

(2017). "Luz e Sombra": Projeto de Cidade e Regimes Territoriais em Favelas da Zona Oeste do Rio de Janeiro. 70f. Monografia (Graduação em Ciências Sociais) - Instituto de Ciências Sociais, Universidade do Estado do Rio de Janeiro. Rio de Janeiro.

DAVIES, Frank.

(2017). Deodoro: formas de governo para uma "região olímpica". Tese (Doutorado em Ciências Sociais) - Universidade do Estado do Rio de Janeiro, Rio de Janeiro.

DE OLIVEIRA, Maria Amália.

(2017). Zona Oeste da cidade do Rio de Janeiro: Entre o rural e o urbano. Iluminuras, v. 18, n. 45, pp. 325-349, ago/dez.

FERNANDES, Adriana dos Santos.

(2014). Escuta ocupação: arte do contornamento, viração e precariedade no Rio de Janeiro. Tese de Doutorado. Programa de Pós-Graduação em Ciências Sociais da Uerj. 
FERNANDES, Nelson.

(2011). O rapto ideológico da categoria subúrbio: Rio de Janeiro, 1858-1945. Apicuri.

FOUCAULT, Michel.

(2000). Microfisica do poder. Rio de Janeiro: Graal.

(2003 [1997]). Society Must Be Defended. Lectures at the College de France, 1975-1976. New York: Picador.

(2017). História da sexualidade I: a vontade de saber. Rio de Janeiro/São Paulo: Paz \& Terra.

FRANCO, Marielle.

(2018). UPP-A redução da favela a três letras: uma análise da política de segurança pública do estado do Rio de Janeiro. São Paulo, N-1 Editora.

FREIRE-MEDEIROS, Bianca.

(2005). O Rio de Janeiro que Hollywood inventou. Rio de Janeiro: Zahar.

GAFFNEY, Christopher.

(2013) "Segurança Publica e os megaeventos esportivos no Brasil". In: SANTOS, 0.; GAFFNEY, C.; RIBEIRO, L. Q. (eds.). Brasil: os impactos da Copa do Mundo 2014 e das Olimpíadas 2016. Letra Capital Editora: Rio de Janeiro, pp. 165184.

(2019). “Can We Blame it on Rio”? Bulletin of Latin American Research 38.3, pp. 267-283.

GIULIANOTI, Richard; KLAUSER, Francisco.

(2010). Security Governance and Sport Megaevents: Toward an Interdisciplinary Research Agenda. Journal of Sport and Social Issues vol. 34, n. 1, pp. 49-61.

GRAHAM, Stephen.

(2012). Foucault's boomerang: the new military urbanism. Development Dialogue, v. 58, n. April, pp. 37-48.

(2017). Cidades sitiadas: o novo urbanismo militar. Boitempo Editorial.

GRILL0, Carolina Christoph; HIRATA, Daniel Veloso.

(2018) A intervenção de interesses privados na segurança pública no Rio de Janeiro. Le Monde Diplomatique Brasil. Edição 130. 2 de maio.
Disponível em: <https://diplomatique.org.br/aintervencao-de-interesses-privados-naseguranca-publica-no-rio-de-janeiro/>.

GUTTERRES, Anelise dos Santos.

(2016). 0 rumor e o terror na construção de territórios de vulnerabilidade na zona portuária do Rio de Janeiro. Mana, v. 22, n. 1, pp. 179209.

\section{INSTITUTO BRASILEIRO DE GEOGRAFIA E} ESTATÍSTICA.

(2010). Censo 2010. Disponível em: <http://www. censo2010. ibge. gov. br/>.

INSTITUTO DE SEGURANÇA PÚBLICA.

(2019). Séries históricas anuais de taxa de letalidade violenta no estado do Rio de Janeiro e grandes regiões. Disponível em: <http://www.ispdados.rj.gov.br/Arquivos/Seri esHistoricasLetalidadeViolenta.pdf>. Acesso em: 17 dez. 2019.

JENSEN, Ole B,

(2016) “New 'Foucauldian Boomerangs': Drones and Urban Surveillance". Surveillance \& society vol. 14, n. 1, p. 20-33.

LEANDER, Anna.

(2017). “Digital/commercial (in) visibility: The politics of DAESH recruitment videos". European Journal of Social Theory vol. 20, n.3, pp. 348372.

LEITE, Márcia Pereira.

(2000). Entre o individualismo e a solidariedade: dilemas da política e da cidadania no Rio de Janeiro. Rev. bras. Ci. Soc. [online], vol.15, n.44, pp. 43-90.

(2014) Entre a 'guerra' e a 'paz': Unidades de Polícia Pacificadora e gestão dos territórios de favela no Rio de Janeiro. Dilemas. revista de estudos de conflito e controle social, v. 7, pp. 625-642.

(2015) De territórios da pobreza a territórios de negócios: dispositivos de gestão das favelas cariocas em contexto de pacificação. In: BIRMAN, Patrícia; LEITE, Marcia Pereira; MACHAD0, Carly; CARNEIRO, Sandra de Sá. (Org.). Dispositivos Urbanos e Trama dos 
Viventes: ordens e resistências. Rio de Janeiro: FGV Editora, v. 1, pp. 377-401.

(2017). State, market and administration of territories in the city of Rio de Janeiro. In: Vibrant - Virtual Brazilian Anthropology, v. 14, n.3. Brasília, ABA. September to December.

LEITE, Márcia Pereira et al.

(2018). Militarização no Rio de Janeiro: da "pacificação" à intervenção. Rio de Janeiro: Mórula.

LUTZ, Catherine.

(2018). Militarization. In: The International Encyclopedia of Anthropology, pp. 1-4.

MACHADO DA SILVA, Luiz Antonio.

(2004). Sociabilidade violenta: por uma interpretação da criminalidade contemporânea no Brasil urbano. Sociedade e estado, v. 19, n. 1, pp. 53-84.

MAGALHÃES, Alexandre.

(2007). A campanha contra o "caveirão" no Rio de Janeiro. Estudos e Pesquisas em Psicologia, v. 7, n. 2, pp. 342-349.

(2013). 0 “legado" dos megaeventos esportivos. a reatualização da remoção de favelas no Rio de Janeiro. Horizontes Antropológicos, (40), pp. 89-118.

MAIA, João Marcelo Ehlert; ROCHA, Lia de Mattos. (2014). Protests, protests, everywhere. Will the "June Journeys" Spoil Brazil's bid for Glory, Cairo Review. n. 12, pp. 79-85.

MENDES, Thiago.

(2017). Rio, cidade sede de um modelo global de militarização. In: Instituto Políticas Alternativas para o Cone Sul. Militarização do cotidiano: um legado olímpico. Rio de Janeiro, pp. 8-11.

MENEZES, Palloma Valle.

(2015). Entre o fogo cruzado e o campo minado: uma etnografia do processo de pacificação de favelas cariocas. Tese de Doutorado. Instituto de Estudos Sociais e Políticos.

(2018). Monitorar, negociar e confrontar: as (re)definições na gestão dos ilegalismos em favelas "pacificadas". Tempo Social, v. 30, n. 3, pp. 191-216.

MIAGUSKO, Edson.

(2016). Esperando a UPP: Circulação, violência e mercado político na Baixada Fluminense. Revista Brasileira de Ciências Sociais, v. 31, n. 91.

MINISTÉRIO DA DEFESA.

(2015). Complexo da Maré: Força de Pacificação já realizou mais de 65 mil ações. Brasília: Notícias, 2015. Disponível em:

<https://www.defesa.gov.br/noticias/15254complexo-da-mare-forcas-de-pacificacao-jarealizaram-mais-de-65-mil-acoes>. Acesso em: 07 fev. 2019.

(2019). Garantia da Lei e da Ordem. Brasília: Exercícios e Operações, Disponível em: $<$ https://www.defesa.gov.br/exercicios-eoperacoes/garantia-da-lei-e-da-ordem>.

Acesso em: 06 fev. 2019.

MISSE, Michel.

(2006). Crime e violência no Brasil contemporâneo: estudos de sociologia do crime e da violência urbana. Editora Lumen Juris.

PALERM0, Luis Claudio.

(2013). Megaeventos e Unidades de Polícia Pacificadora: representações sobre o lugar das favelas no tecido urbano. Ilha Revista de Antropologia, v. 15, n. 1, 2, pp. 311-330.

PI0, Leopoldo Guilherme.

(2014). Preservando o presente: Novos usos e sentidos do patrimônio no projeto Porto Maravilha. Tese de Doutorado - Programa de Pós-Graduação em Ciências Sociais da Universidade do Estado do Rio de Janeiro.

RAMOS, Silvia (coord.).

(2019). Retratos da Violência - Cinco meses de monitoramento, análises e descobertas. Rio de Janeiro: Rede de Observatórios da Segurança/CESeC, novembro.

RIBEIRO, Ludmila; VILAROUCA, Marcio Grijó.

(2018). “Ruim com ela, pior sem ela": o desejo de continuidade das UPPs para além das Olimpíadas. Revista de Administração Pública, 52(6), pp. 1155-1178. 
RIBEIRO, Luiz Cesar; SANTOS JR, Orlando Alves.

(2013). “Governança empreendedorista e megaeventos esportivos: reflexões em torno da experiência brasileira". O social em questão, ano $X V I$, n. 29, pp. 23-42.

ROCHA, Lia de Mattos.

(2016). "10 anos de Beltrame: segurança pública no Rio de Janeiro". Blog Junho, publicado em 14 de novembro de 2016. Disponível em: $<$ <ttp://blogjunho.com.br/10-anos-debeltrame-seguranca-publica-no-rio-dejaneiro/>.

(2018). Democracia e militarização no Rio de Janeiro: "pacificação", intervenção e seus efeitos no espaço público. In: LEITE, M. P. et al. (org), Militarização no Rio de Janeiro: da "pacificação" à intervenção. Rio de Janeiro: Mórula Editorial, pp. 223-239.

SÁNCHEZ, Fernanda et al.

(2013). Cidade-Marca e disputas simbólicas no projeto Rio 2016. In: XV Enanpur, Recife. Anais do XV Encontro Nacional da Associação Nacional de Pós-Graduação em Planejamento Urbano.

SHELLER, Mimi.

(2013). “The islanding effect: post-disaster mobility systems and humanitarian logistics in HaitI". Cultural Geographies vol. 20, n.2, p. 185204.
SIQUEIRA, Raíza.

(2013). A Política no Loteamento: Um estudo sobre mediação na Zona Oeste carioca. Tese de Doutorado. Tese de Doutorado. Instituto de Estudos Sociais e Políticos-IESP/Universidade do Estado do Rio de Janeiro.

SOARES, Luiz Eduardo.

(1996). Violência e política no Rio de Janeiro. Rio de Janeiro, Relume-Dumará.

VAINER, Carlos.

(2011). Cidade de Exceção: Reflexões a partir do Rio de Janeiro. Anais do XIV Encontro Nacional da Associação Nacional de Planejamento Urbano (ANPUR), vol. 14, n.1, pp. 231-248.

WALL, Tyler.

(2013). Unmanning the police manhunt: Vertical security as pacification. Socialist Studies/Études Socialistes, v. 9, n. 2.

ZIMBALIST, Andrew.

(2015). Circus maximus: The economic gamble behind hosting the Olympics and the World Cup. Brookings Institution Press.

\section{Recebido em}

janeiro de 2020

Aprovado em

julho de 2020 